\title{
Similarities and Differences of Pumping Conventional and Self-Compacting Concrete
}

\author{
Dimitri Feys ${ }^{1}$, Geert De Schutter ${ }^{2}$, Ronny Verhoeven ${ }^{3}$ and Kamal H. Khayat ${ }^{1}$ \\ ${ }^{1}$ Department of Civil Engineering, Université de Sherbrooke, Québec, Canada \\ ${ }^{2}$ Magnel Laboratory for Concrete Research, Department of Structural Engineering, \\ Faculty of Engineering, Ghent University, Belgium \\ ${ }^{3}$ Hydraulics Laboratory, Department of Civil Engineering, Faculty of Engineering, \\ Ghent University, Belgium
}

\begin{abstract}
In practice, self-compacting concrete (SCC) is considered as a simple extension of conventional vibrated concrete (CVC) when pumping is concerned. The same equipment, materials, pumping procedures and guidelines used for CVC are applied when pumping SCC. On the other hand, it has been clearly shown that the rheological properties and the mix design of SCC are different than CVC. Can the same pumping principles employed for CVC be applied for SCC? This paper compares the some published results of pumping of CVC with those for SCC. A first striking difference between pumping of CVC and SCC is the flow behaviour in the pipes. The flow of CVC is a plug, surrounded by a lubricating layer, while during the flow of SCC, part of the concrete volume itself is sheared inside the pipe. As a result, the importance of viscosity increases in case of SCC. Due to the low yield stress of SCC, the behaviour in bends is different, but quite complex to study. Due to the lower content of aggregate and better stability of SCC, as it is less prone to internal water migration, blocking is estimated to occur at lower frequency in case of SCC.
\end{abstract}

\section{Introduction}

Pumping of concrete is a worldwide applied casting method enabling fast and efficient concrete placement. For conventional vibrated concrete (CVC), the results of scientific investigations and practical guidelines can be easily found in literature [1-4], while for self-compacting concrete (SCC), the number of investigations published is quite restricted [5-7]. On the contrary, SCC is largely applied in the concrete industry and is often placed by means of pumping. In practice, it is assumed that pumping of SCC is similar to pumping of CVC, and that the same 
rules would apply. On the other hand, SCC is a different concrete with a different composition and rheological behaviour [7,8]. Therefore, it is important to know if the rules for CVC would apply for SCC.

This paper compares the literature results for pumping of CVC with the results obtained during a research project on pumping of SCC. It will point out the main differences in mix design and rheological properties between the two concrete types and the consequences of these differences on the main parameters influencing the pumping pressure.

\section{Experiments on SCC}

\section{Test setup}

Pumping experiments on SCC were conducted with a truck-mounted piston pump, having two cylinders alternately pushing concrete inside the pipeline and pulling concrete from the reservoir of the pump. A powerful valve in the pump switches the connection between the pipes and the cylinders when the pushing cylinder is empty and the pulling cylinder is full. The output discharge rate of the pump could be varied over 10 different steps from the lowest step: 4-5 1/s (defined as step 1) to the highest step: 40 1/s (step 10). During the experiments, the maximum discharge rate was restricted to $19-201 / \mathrm{s}$ (step 5) for safety reasons.

Behind the pump, two different types of loop circuits were installed using steel pipes with an inner diameter of $106 \mathrm{~mm}$ : a short circuit with a length of approximately $25 \mathrm{~m}$ (Figure 1), and long circuits with lengths varying between 80 and $105 \mathrm{~m}$. In both types of circuits, the pressure loss was measured in a straight horizontal section by means of two pressure sensors, located approximately $10 \mathrm{~m}$ from each other. As a back-up for the each pressure sensor, three strain gauges were attached to the outer wall of the pipe. As pipe deformation can be related to the occurring pressure [1], strain gauges were also attached to the pipe walls in other locations than the pressure sensors to monitor pressure evolution in the long circuits, including sections containing a bend.

As the theoretical volume of a pumping cylinder is 83.1 liter, the discharge rate was determined indirectly by measuring the time between two changes of the pumping valve, which corresponds to the contents of one pumping cylinder. This measuring method was verified by pumping the concrete present inside a full cylinder into a reservoir suspended with a load cell to a rolling bridge. By measuring the variations of the mass of the concrete discharged into the reservoir with time, the discharge rate was calculated. Both measurement methods were shown to deliver similar discharge rates. 


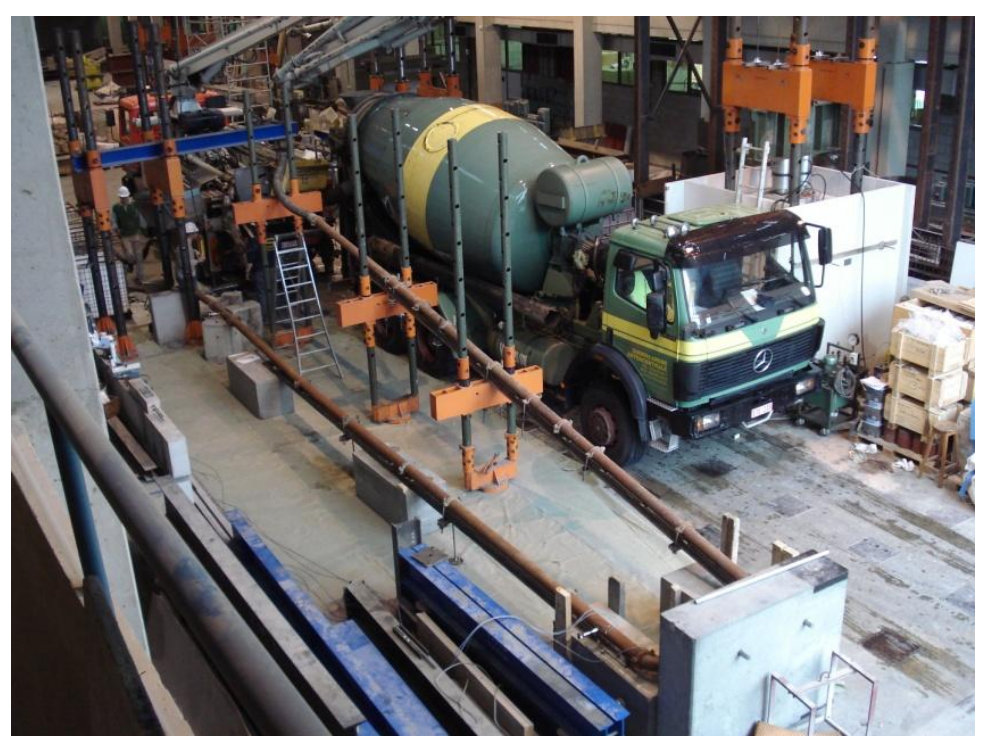

Figure 1. Short pumping circuit (25 m).

\section{Testing procedure}

As the volume of concrete required for the pumping tests was 1.5 and $3.25 \mathrm{~m}^{3}$ for the short and long circuits, respectively, the concrete was prepared in a ready-mix plant and delivered to the laboratory in a time span of approximately $45 \mathrm{~min}$. After filling the pipe with concrete over $10 \mathrm{~min}$ for the short circuit, the first test could be started around $60 \mathrm{~min}$ following water-cement contact. For the long circuits, the quantity of priming mortar appeared to be insufficient to avoid blocking during the filling of the pipes and consequently, the first test was started at later concrete ages: between 1 and 2 hours. The tests on fresh concrete indicate that even at this age, the concrete still has self-compacting properties.

The testing procedure consisted of pumping the concrete at the five lowest available discharge rates, in a descending order (steps 5 to 1 ) and maintaining each discharge rate for five full strokes (Figure 2). In this way, pressure loss, measured as the pressure difference between the two pressure sensors divided by the separation distance, vs. discharge rate curve could be obtained in relatively short period $(4 \mathrm{~min})$. This procedure was repeated at 30-min intervals until the workability of the concrete decreased below the SCC level. Simultaneously to the pumping experiment, rheological properties of the SCC were determined using a Tattersall Mk-II rheometer [7, 9] in addition to standard characterization of SCC workability (slump flow, V-funnel and sieve stability in addition to unit weight and air content). 


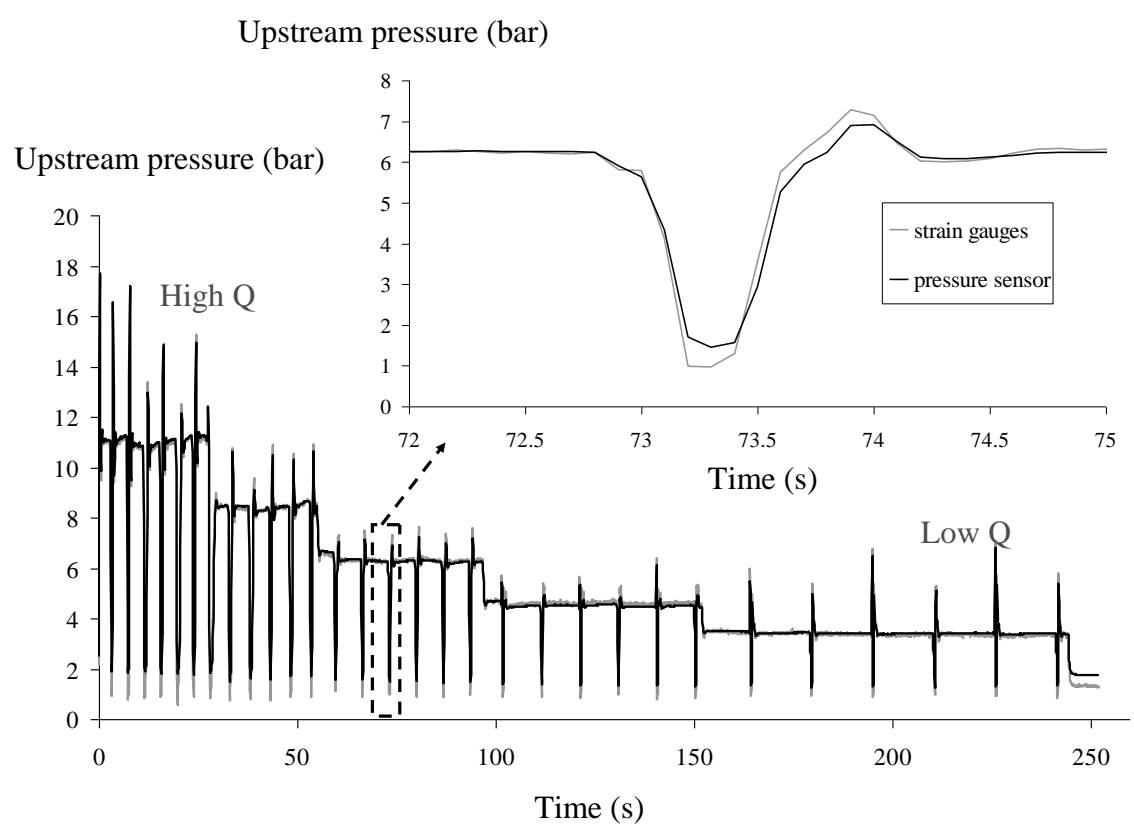

Figure 2. Upstream pressure variation with time, clearly indicating the five different discharge rate steps.

\section{Concrete composition}

In total, 19 different concrete mixtures were produced for the pumping tests. The mixture proportioning of these concretes are given in Table I. Most of the mixtures were prepared using ordinary high strength Portland cement (CEM I with 52.5 $\mathrm{MPa}$ cement strength at 28 days), limestone filler, natural sand, rounded river-bed gravel with maximal size of $16 \mathrm{~mm}$ and polycarboxyl-ether superplasticizer with a long workability retention. As can be seen in Table I, the mixture proportioning is based on the powder-type method for SCC mix design [8]. Four of the concrete mixtures were commercial products supplied by the ready-mix concrete producer. Mixtures SCC 14-17 were pumped in the long circuits, the others were used in the short circuit. 
Table I. Concrete compositions.

\begin{tabular}{|c|c|c|c|c|c|c|c|c|c|c|}
\hline $\begin{array}{l}\text { Composition } \\
{\left[\mathrm{kg} / \mathrm{m}^{3}\right]}\end{array}$ & SCC 0 & SCC 1 & SCC 2 & SCC 3 & $\operatorname{SCC} 4$ & SCC 5 & SCC 6 & SCC 7 & $\operatorname{SCC} 8$ & CVC 1 \\
\hline Gravel 8/16 & \multirow{7}{*}{ 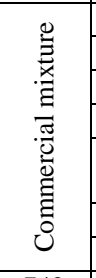 } & 434 & 434 & 434 & 459 & 434 & 434 & 434 & 434 & \multirow{8}{*}{ 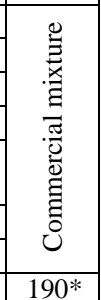 } \\
\hline Gravel 2/8 & & 263 & 263 & 263 & 278 & 263 & 263 & 263 & 263 & \\
\hline Sand $0 / 5$ & & 853 & 853 & 853 & 901 & 853 & 853 & 853 & 853 & \\
\hline CEM I $52.5 \mathrm{~N}$ & & 360 & 360 & 360 & 300 & 360 & 360 & 360 & 360 & \\
\hline $\begin{array}{l}\text { Limestone } \\
\text { Filler } \\
\end{array}$ & & 239 & 239 & 239 & 200 & 239 & 239 & 239 & 239 & \\
\hline Water & & 165 & 165 & 165 & 165 & 165 & 165 & 165 & 165 & \\
\hline $\mathrm{SP}\left[1 / \mathrm{m}^{3}\right]$ & & 11 & 11 & 15.22 & 12.16 & 20.95 & 13.33 & 12.69 & 14.44 & \\
\hline Initial SF [mm] & 740 & 640 & 720 & 690 & 710 & 710 & 720 & 650 & 680 & \\
\hline
\end{tabular}

\begin{tabular}{|c|c|c|c|c|c|c|c|c|c|}
\hline $\begin{array}{l}\text { Composition } \\
{\left[\mathrm{kg} / \mathrm{m}^{3}\right]}\end{array}$ & SCC 9 & SCC 10 & SCC 11 & SCC 12 & SCC 13 & SCC 14 & SCC 15 & SCC 16 & SCC 17 \\
\hline Gravel 8/16 & 410 & 434 & 410 & 434 & 434 & 434 & \multirow{7}{*}{ 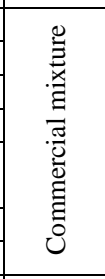 } & 434 & \multirow{8}{*}{ 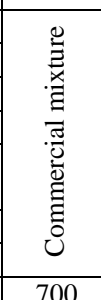 } \\
\hline Gravel 2/8 & 248 & 263 & 248 & 263 & 263 & 263 & & 263 & \\
\hline Sand $0 / 5$ & 805 & 853 & 805 & 853 & 853 & 853 & & 853 & \\
\hline CEM I $52.5 \mathrm{~N}$ & 400 & 360 & 400 & 360 & 360 & 360 & & 360 & \\
\hline $\begin{array}{l}\text { Limestone } \\
\text { Filler }\end{array}$ & 300 & 239 & 300 & 239 & 239 & 239 & & 239 & \\
\hline Water & 165 & 165 & 165 & 165 & 165 & 160 & & 165 & \\
\hline SP $\left[1 / \mathrm{m}^{3}\right]$ & 18.15 & 11 & & & & 21.9 & & & \\
\hline Initial SF [mm] & 850 & 800 & 700 & 675 & 700 & 640 & 650 & 700 & \\
\hline
\end{tabular}

\section{Comparison between CVC and SCC}

\section{Mix design and rheological properties}

As stated in the previous sections, the mix design of SCC differs from CVC in order to enhance the flowability, reduce blocking due to accumulation of aggregates and avoid segregation. The amount of coarse aggregates in SCC is reduced and the viscosity of the concrete is increased by means of viscositymodifying agents (VMA), or by increasing the amount of fine particles in the concrete, or by combining both. In this experimental project, the powder-type method was applied, by adding limestone filler to the concrete.

The rheological behaviour of fresh concrete is mostly described by means of the Bingham model (defining a yield stress and a plastic viscosity) [9-11], when transient behaviour, like thixotropy is not considered [11]. As generally known, SCC has a low yield stress, resulting in a high slump value [12]. The order of magnitude for the yield stress is between 10 and $100 \mathrm{~Pa}$ for SCC, while it can achieve several thousands of Pascals for CVC. For "pumpable" conventional vibrated concrete, the yield stress roughly varies between 100 and $1000 \mathrm{~Pa}$ [1]. The viscosity of SCC is increased by means of VMA or an additional amount of small 
particles to prevent segregation of the coarse aggregates. As a result, the viscosity of SCC is generally higher than the viscosity of CVC.

\section{Behaviour law in pipes}

The movement of concrete in pipes can be determined by two physical processes: flow or friction $[1,13]$. In case friction is negligible, the deformation of concrete in pipes occurs according to the hydrodynamic laws, and as concrete has a high viscosity, the occurrence of turbulence in straight sections is quite rare. As a result, the flow is laminar, and rheological principals for dense suspensions can be applied.

The pressure gradient during pumping does not only push the concrete through the pipeline, but also tends to move the water among the granular skeleton [13]. In this case, the water content is no longer homogeneous along the conveying pipeline and in zones suffering a reduction in water, the stress is no longer transferred through the liquid, but by friction among aggregates. Browne and Bamforth examined both behaviour laws for the movement of concrete in pipes and concluded that the frictional behaviour causes a significantly higher pressure to pump the concrete, compared to the hydrodynamic behaviour [13]. Also in practice, "pumpable" CVC contains relatively large amount of fine particles to reduce friction, and stable concrete is less prone to friction than unstable mixtures.

As discussed in the previous section, special care is taken to avoid segregation in case of SCC, by adding VMA or more fine particles [8]. In theory, SCC should flow in the pipes according to hydrodynamic laws, which is confirmed by the conducted experiments. No blocking was observed during regime conditions (after insertion), even when a segregating concrete was fed into the pump (SCC 9 and 10). During the start-up of pumping, on the other hand, the experiments on the long circuits indicate a large amount of blockings due to a lack of fine particles at the concrete front, causing friction between coarse aggregate particles. The amount of fine particles at the concrete front decreases, as they stick to the pipe wall to lubricate the concrete and as they need to fill the space in the rubber seals installed in the connections between the pipes. Blocking during start-up was reported by Kaplan as the most frequent blocking occurrence [1] and can be prevented by inserting a priming mortar in the pipes before the pumping of concrete starts.

\section{Flow in straight sections - velocity profile}

In order to estimate the velocity profile of different types of concrete flowing through pipes, the theoretical framework for laminar flow in cylindrical pipes will be introduced, which is known as the Poiseuille formula in case of Newtonian liquids. The shear stress at the wall of the pipe is related to the pressure loss by equilibrium of forces (Eqn. (1)): 


$$
\tau_{w}=\Delta p \cdot R / 2
$$

where: $\tau_{\mathrm{w}}=$ wall shear stress $(\mathrm{Pa})$

$\Delta \mathrm{p}=$ pressure loss per unit of length $(\mathrm{Pa} / \mathrm{m})$

$\mathrm{R}=$ radius of the pipe $(\mathrm{m})$

The shear stress varies linearly with the pipe radius, from zero in the center, to the maximum value at the wall $\left(\tau_{\mathrm{w}}\right)$. Incorporating the rheological behaviour law into the shear stress profile delivers the shear rate distribution, which can be integrated to obtain the velocity profile. The presence of a yield stress causes a zone with zero shear rate in the center, resulting in a constant velocity, also known as the plug. The larger the yield stress, the larger the plug radius and in the limit, no flow should occur if the wall shear stress is equal to or smaller than the yield stress of the concrete. As the yield stress of CVC is quite high, this would result in elevated pressure to start the flow of CVC. In order to facilitate its movement in pipes, concrete creates a water-cement layer of lower rheological properties near the wall [1-2]. As a result, the concrete can move much faster through the pipes and flow is observed even if the wall shear stress is lower than the yield stress of the bulk concrete.

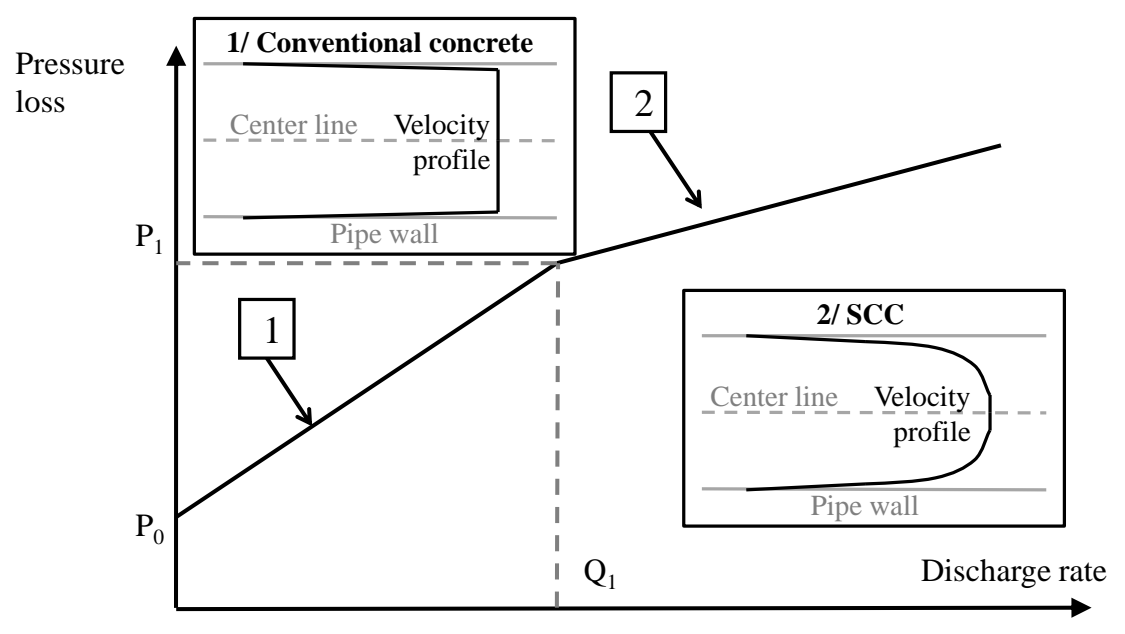

Figure 3. Distinction between pure plug flow with a lubrication layer (zone 1) and plug flow with a lubrication layer and partly sheared concrete (zone 2), based on pressure loss - discharge rate curve. $(\mathrm{Q} 1, \mathrm{P} 1)$ represents the theoretical point where the wall shear stress equals the concrete yield stress. Figure after Kaplan [1]. 
Kaplan made a distinction between two different types of velocity profiles of the pressure loss - discharge rate curve, as can be seen in Figure 3 [1]. In zone 1, on the left side, the pumping parameters are only governed by the properties of the lubrication layer, as the wall shear stress is lower than the concrete yield stress. In zone 2 , the flow parameters are governed by both the properties of the lubrication layer and the properties of the concrete. The velocity profile in zone 1 consists of a plug (constant velocity) and a large velocity gradient near the wall due to the lubrication layer $[1,2]$, while in zone 2 , the velocity profile consists of a plug, a large velocity gradient near the wall and a smaller velocity gradient in between, because the concrete itself is also sheared $[1,7]$. Conventional concrete has a rather high yield stress and in most cases is situated in zone 1, while SCC has a rather low yield stress, and is mostly situated in zone 2 .

SCC also creates a lubrication layer near the wall during pumping, as the theoretical framework delivers significantly larger pressure losses at a certain discharge rate, compared to the experiments [7]. On the other hand, as the yield stress is low, a large part of the concrete is sheared, and a good relationship between the viscosity of the concrete and pressure loss can be established. This relationship is dependent on the discharge rate (Figure 4).

Pressure loss $(\mathrm{kPa} / \mathrm{m})$

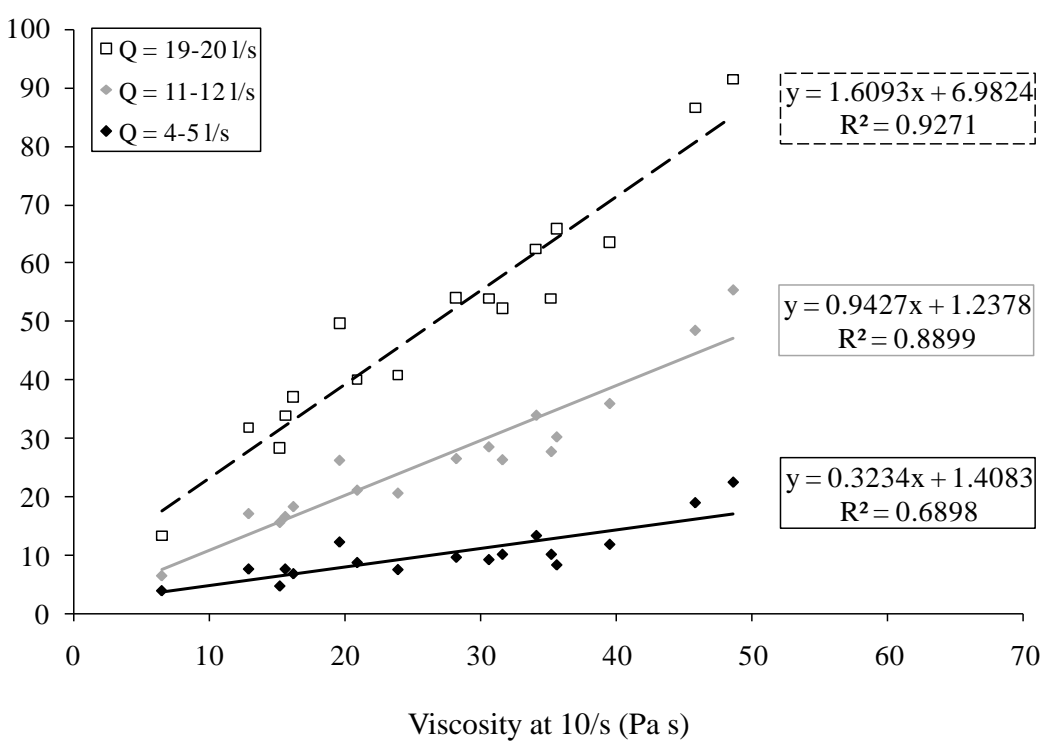

Figure 4. Variations of pressure loss with plastic viscosity of SCC determined at different discharge rates. 
Note that these results are empirical and the relationship will change with varying discharge rate and pipe diameter. On the other hand, it is clearly shown that viscosity of SCC, rather than the yield stress, is the main factor influencing pressure loss. Such pressure loss corresponds to the required pumping pressure. Further research should be carried out to identify the relative importance of the lubrication layer for pumping SCC.

\section{Pressure loss in bends}

As in case for pure water, existing literature delivers non-conclusive results regarding pressure loss in bends of pipelines for CVC. For example, Kaplan [1] and Chapdelaine [2] did not observe any noticeable additional pressure losses in bends in during their field pumping experiments, while practical guides for pumping introduce the concept of equivalent length to account for the presence of bends in pumplines [3, 4]: e.g. one bend of $90^{\circ}$ is equivalent to $3 \mathrm{~m}$ of straight pipes [4].

For SCC flowing in bends, an additional pressure loss was observed during the pumping experiments in the long circuits, which appears to be larger compared to CVC. It is important to note that the large scatter of the results prevents accurate conclusion on the level of increase in pressure loss in bends [7]. As the concrete flow needs to change direction across a bend, it is estimated that pressure loss in bends is influenced by a large number of parameters, including viscosity, inertia, coarse aggregate properties, bending radius and helicoidal flow velocity. As a result, further research is needed to capture these phenomena in details in order to develop guidelines and models that can take into account flow of SCC in bends.

\section{Conclusions}

By means of the results available in literature for $\mathrm{CVC}$ and experimental research project on pumping of SCC, comparison between pumping of CVC and SCC was made. The velocity profile for CVC flowing through pipes is composed of a lubrication layer with a large velocity gradient and a plug in which the velocity is constant. For SCC, the radius of the plug is much smaller than for CVC, and a smaller velocity gradient is present between the lubrication layer and the plug. As a result, a part of the concrete volume is also sheared in the pipes. The pumping parameters for CVC depend mainly on the properties of the lubrication layer, while for SCC, a good relationship between concrete viscosity and pressure loss was established. The flow in bends is complicated leading to non-conclusive results for both CVC and SCC. Further research is required to clarify the influencing factors. 


\section{Acknowledgements}

The authors would like the acknowledge the Research Foundation in Flanders (FWO) for the financial support of the project and the technical staff of the Magnel and Hydraulics laboratory at Ghent University for the preparation and execution of the full scale pumping tests.

\section{References}

[1] Kaplan, D. (2001), Pumping of concretes, Ph-D dissertation (in French), Laboratoire Central des Ponts et Chausées, Paris.

[2] Chapdelaine, F. (2007), Fundamental and practical study on the pumping of concrete, Ph-D-thesis (in French), Université Laval, Laval.

[3] Guptill, N.R. et al. (ACI-Comm 304) (1998), Placing concrete by pumping methods, American Concrete Institute, Farmington Hills.

[4] Crepas, R.A. (1997), Pumping concrete, techniques and applications, 3rd edition, Crepas and Associates, Inc., Elmhurst.

[5] Beitzel, H. and Beitzel. M. (2008), Pump application for self-compacting concrete under extreme conditions, Proc. of the 3rd North-American Conf. on the Design and Use of Self-Consolidating Concrete, Chicago.

[6] Ouchi, M. and Sakue, J. (2008), Self-compactability of fresh concrete in terms of dispersion and coagulation of particles of cement subject to pumping, Proc. of the $3^{\text {rd }}$ North-American Conf. on the Design and Use of Self-Consolidating Concrete, Chicago.

[7] Feys, D. (2009), Interactions between rheological properties and pumping of self-compacting concrete, Ph-D-thesis, Ghent University, Ghent.

[8] De Schutter, G., Bartos, P., Domone, P. and Gibbs, J. (2008), SelfCompacting Concrete, Whittles Publishing, Caithness.

[9] Tattersall, G.H. and Banfill, P.F.G. (1983), The rheology of fresh concrete, Pitman, London.

[10] Wallevik, O.H. (2003), Rheology - A scientific approach to develop selfcompacting concrete, Proc. of the 3rd Int. Symp. on Self-Compacting Concrete, Reykjavik, pp. 23-31.

[11] Wallevik, J.E. (2009), Rheological properties of cement paste: Thixotropic behavior and structural breakdown, Cem. Conc. Res.2 vol. 39, pp. 14-29.

[12] Ede, A.N. (1957), The resistance of concrete pumped through pipelines, Mag. Conc. Res., vol. 9, pp. 129-140.

[13] Browne, R.D. and Bamforth, P.B. (1977), Tests to establish concrete pumpability, ACI-Journal, vol. 74, pp. 193-203. 